-Nota-

\title{
AGRICULTURA FAMILIAR NAS ZONAS PERIFÉRICAS COMO EQUILÍBRIO À VERTICALIZAÇÃO INTENSA DE CIDADES BRASILEIRAS: UM ENFOQUE LEGAL E SOCIAL ${ }^{1}$
}

\author{
Miguel Etinger de Araujo \\ Doctor en Derecho de la Ciudad \\ Universidade do Estado do Rio de Janeiro - UERJ, Brasil \\ miguel.etinger@gmail.com \\ ERIKA JULIANA DMITRUK \\ Maestría en Filosofía y Teoría del Derecho \\ Universidade Federal de Santa Catarina - UFSC, Brasil \\ Estudiante de doctorado en Servicio Social y Política Social \\ ejdmitruk@hotmail.com \\ Karina Alves TeIXeIra SANTOS \\ Maestría en Derecho Negocial \\ Universidade Estadual de Londrina - UEL, Brasil \\ karina.teixeira.adv@hotmail.com
}

Recebido: 30 de setembro de 2014 / Aceito: 10 de março de 2016

RESUMO: Analisando o processo de urbanização das cidades ao redor do mundo, e especialmente no Brasil, observa-se que os mecanismos tradicionais para compensação dos impactos urbano-ambientais dos empreendimentos não têm conseguido, na maioria

\footnotetext{
${ }^{1}$ Este artigo vem sendo desenvolvido ao longo dos anos, tendo sido apresentado em outras versões anteriores no VI Encontro Nacional do ANPPAS, em Belém/PA, Brasil, 2012; no 12th Colloquium 2014 of the IUCN Academy of Environmental Law, Tarragona, Espanha, 2014 : e no International Symposium Sustainable Rural Development In Peripheral Regions, Zwierzyniec, na Polônia, 2014.
} 
das vezes, promover melhorias no campo social e urbanístico, ensejando, portanto, o questionamento sobre o aperfeiçoamento destes mecanismos. Sem deixar de reconhecer a importância e efetividade de algumas experiências, neste artigo propõe-se garantir a formação de espaços para agricultura familiar em periferias urbanas, através da intervenção estatal em atividades privadas, com a finalidade de conciliar os interesses econômicos, sociais e ambientais. A hipótese é de que, no sistema capitalista, as regras de mercado não conseguem produzir um ambiente capaz de atender às demandas coletivas e individuais da cidade. A instituição dessas áreas periurbanas para a fixação de famílias voltadas para a produção de alimentos pode conter a expansão urbana desordenada, incentivar a produção de alimentos mais baratos e mais saudáveis, resultando na diminuição dos custos de transporte dos produtos e diminuição da utilização de agrotóxicos. Assim, a partir de uma metodologia indutiva com estudo de caso em uma cidade media brasileira até uma premissa geral, pretende-se investigar as possibilidades jurídico-sociais da intervenção estatal mencionada. Com base em uma técnica baseada na revisão da literatura sobre o tema e com estudo de caso para discutir experiências concretas que podem confirmar a hipótese inicial, este artigo procura apontar alternativas na promoção de cidades sustentáveis.

ABSTRACT: After analyzing the urbanization process of cities all over the world, especially in Brazil, it can be observed that traditional mechanisms try to compensate the environmental impact of various enterprises. However, these methods have not been able to achieve significant improvements in social and urban aspects of life, leading researchers to question if these mechanisms can and will be perfected. This paper proposes that there is a way to consolidate economic, social, and environmental interests through state intervention in private sectors, which, without forgetting to recognize the importance and the effectiveness of certain experiences, can guarantee the establishment of spaces for family farming in the suburb. This paper's hypothesis is based on the concept that in capitalistic systems, the market's systematic rules are not able to develop an environment capable of attending to cities collective and individual demands. Therefore, the implementation of suburban areas so that families can produce food may also be a way to stop the disoriented urban expansion and incentivize production of cheaper and healthier meals, resulting in the reduction of transportation costs and the use of agro-toxics. Thus, from using inductive reasoning built on a 
specific case study in a Brazilian medium sized city to concluding with a general premise, this paper aims to investigate the legal and social possibilities of state intervention. Utilizing a method based on various academic works on this topic and using a case study that discusses concrete experiences confirming the initial hypothesis, this paper tries to point out alternatives that can help promote sustainable cities.

RESUMEN: Analizando el proceso de urbanización de las ciudades alrededor del mundo y, especialmente en Brasil, observase que los mecanismos tradicionales para compensación de los impuestos urbanos-ambientales de las empresas no han logrado, la mayoría de las veces, promover mejoras en el campo social y urbanístico, justificando, por lo tanto, el cuestionamiento de dichos mecanismos. Es por ello que se podría hablar del perfeccionamiento de dichos mecanismos, sin dejar de reconocer la importancia y efectividad de algunas experiencias. En este artículo se propone analizar la formación de espacios para la agricultura familiar en las periferias urbanas, a través de la intervención estatal en las actividades privadas, con la finalidad de conciliar los intereses económicos, sociales y ambientales. La hipótesis es que, en el sistema capitalista, las reglas del mercado no logran producir un ambiente capaz de atender a las demandas colectivas e individuales en la ciudad. La instauración de dichas áreas periurbanas para la ubicación de familias destinadas a la producción de alimentos podría detener la expansión urbana desordenada, incentivar la producción de alimentos más baratos y más saludables, resultando en la disminución de los costos de transporte de los productos y de la utilización de agrotóxicos. Así, a partir de la metodología inductiva con estudio de caso en una ciudad media brasileña hasta una conclusión general, se pretenden investigar las posibilidades jurídico-sociales de la intervención estatal mencionada. A partir de una técnica basada en la revisión de la literatura sobre el tema y con un estudio de caso para discutir experiencias concretas que pueden confirmar la hipótesis inicial, este artículo procura apuntar alternativas en la promoción de ciudades sustentables.

RESUM: Analitzant el procés d'urbanització de les ciutats arreu del món i, especialment, a Brasil, s'observa que els mecanismes tradicionals per a compensació dels impostos urbans ambientals de les empreses no han aconseguit, la majoria de les 
vegades, promoure millores en el camp social i urbanístic, qüestionant l'adequació d'aquests mecanismes. És per això que es podria parlar del perfeccionament d'aquests mecanismes, sense deixar de reconèixer la importància i efectivitat d'algunes experiències. En aquest article es proposa estudiar la formació d'espais per a l'agricultura familiar en les perifèries urbanes, a través de la intervenció estatal en les activitats privades, amb la finalitat de conciliar els interessos econòmics, socials $\mathrm{i}$ ambientals. La hipòtesi és que, en el sistema capitalista, les regles del mercat no aconsegueixen produir un ambient capaç d'atendre a les demandes col·lectives i individuals a la ciutat. La instauració d'aquestes àrees periurbanes per a la ubicació de famílies destinades a la producció d'aliments podria aturar l'expansió urbana desordenada, incentivar la producció d'aliments més barats i més saludables, amb el resultat de la disminució dels costos de transport dels productes i de la utilització d'agrotòxics. Així, a partir de la metodologia inductiva amb l'estudi de cas d'una ciutat mitjana brasilera fins a una conclusió general, es pretén investigar les possibilitats jurídic-socials de la intervenció estatal esmentada. A partir d'una tècnica basada en la revisió de la literatura sobre el tema i amb estudi de cas per discutir experiències concretes que poden confirmar la hipòtesi inicial, aquest article procura apuntar cap aalternatives en la promoció de ciutats sostenibles.

PALAVRAS-CHAVE: Urbanização — Sociedade de Risco - Atividade Imobiliária — Compensação - Agricultura Familiar.

KEYWORDS: Urbanization — Risk Society — Real Estate Activity — Compensation - Familiar Agriculture.

PALABRAS CLAVE: Urbanización - Sociedad del riesgo - Actividad inmobiliaria - Compensación - Agricultura familiar.

PARAULES CLAU: Urbanització - Societat del risc - Activitat immobiliària Compensació - Agricultura familiar. 
Sumário: I. Introdução. II. Contornos de uma sociedade de risco e estado de direito socioambiental. III. Riscos na atividade urbana: a atividade imobiliária. IV. O urbano interagindo com o rural. V. Conclusões articuladas. VI. Referências bibliográficas.

\section{INTRODUÇÃO}

A compatibilização entre as diversas atividades produtivas em determinados espaços territoriais é uma questão latente em várias partes do mundo, a demonstrar a necessidade de se discutir criticamente os modelos postos e propor alternativas factíveis.

A questão ambiental é paradigmática, quando expõe o conflito entre a preservação dos recursos naturais, possibilitando que os ecossistemas exerçam suas funções regulatórias, e ainda permitindo um aproveitamento econômico por particulares.

No meio ambiente urbano esta questão apresenta-se de maneira mais impactante, na medida em que a população mundial tornou-se preponderantemente urbana, com alguns municípios tendo que apresentar soluções imediatas para questões como falta de moradia, mobilidade, poluição, etc. Em regra, este cenário ocorre nos locais em que o planejamento urbano tem sido colocado em segundo plano, em favor dos lucros decorrentes do processo de urbanização.

Ainda no ambiente urbano, e em decorrência do aumento da população nestes espaços, bem como da mutação do capital especulativo para o capital imobiliário (resultante das constantes crises econômico-financeiras mundiais do sistema capitalista), tem-se verificado, em especial no Brasil, um forte crescimento da atividade imobiliária em áreas urbanas.

Essa crescente demanda por espaços para construção das cidades tem também seus efeitos negativos, na medida em que há uma forte demanda por usos não diversificados no espaço urbano, priorizando-se aqueles que podem render lucro a determinada parcela da população. E estes usos podem trazer efeitos colaterais negativos, como segregação socioespacial, degradação ambiental, ou a falta de mobilidade. Tais fatores indicam uma via contrária à ideia de sustentabilidade, entendida como a situação de equilíbrio entre os diversos interesses no processo de ocupação do solo urbano. Resumidamente, são os tradicionais aspectos mencionados pela doutrina: ambiental, social e econômico.

Neste sentido, toma importância a atuação do Estado de Direito Socioambiental, terminologia utilizada para representar um Estado que tem como dever legal a 
preservação ambiental e equilíbrio social, devendo atuar na regulação das diversas atividades, de modo a impedir ou mitigar seus impactos negativos.

No Brasil, os mecanismos adotados até então para a compensação destes impactos nem sempre têm alcançado resultados satisfatórios, propondo-se neste trabalho, de forma alternativa, o fomento à agricultura familiar em áreas urbanas ou periurbanas. Como exemplo, ao se instituir um zoneamento voltado para atividades agrícolas de pequeno porte nas franjas urbanas, controla-se o processo de expansão do perímetro urbano. Este fato pode levar, por exemplo, à efetivação de moradia adequada para famílias que residam nestas áreas periféricas, produção de alimentos mais saudáveis e a um preço menor, utilização dos vazios urbanos, combatendo a especulação imobiliária.

Este modelo visa atender aos interesses ambientais e sociais, conformando ainda a legitimidade e a legalidade da atividade econômica, como determina o sistema jurídico brasileiro, e o Direito possui mecanismos adequados para direcionar o tipo de atividade que deverá ser exercida em cada espaço da cidade.

A seguir, pretende-se construir um eixo agregador dos diversos institutos mencionados supra, de forma a construir um modelo que permita ser implementado de acordo com a conveniência e possibilidade de cada realidade.

\section{CONTORNOS DE UMA SOCIEDADE DE RISCO E ESTADO DE DIREITO SOCIOAMBIENTAL}

Nenhuma atividade que altere o meio ambiente é inócua. Por menor que seja, sempre haverá alguma consequência, que pode ser positiva ou negativa, local ou regional, prevista ou não prevista.

Os chamados riscos ambientais, na proporção em que se apresentam hoje em dia, não surgiram somente nas últimas décadas, com a centralização do capital, a mobilidade social e o consumo em massa. Em verdade, a modernidade apenas tornou ainda mais evidente os efeitos dos riscos ambientais decorrentes de interregnos mais remotos.

De acordo com $\mathrm{BECK}^{2}$, o mundo, ao sofrer uma brusca guinada consubstanciada na transposição da sociedade feudal e agrária para a capitalista e industrial, enfrentou uma

\footnotetext{
${ }^{2}$ BECK, U., Sociedade de Risco: rumo a uma outra modernidade, (Tradução de Sebastião Nascimento), Ed. 34, São Paulo, 2010, p. 170.
} 
ruptura dentro da modernidade, em razão do estabelecimento de um inovador método de produção e distribuição de bens, promovedor de desigualdades, que afastou a clássica sociedade industrial (primeira modernidade) fazendo emergir a sociedade de risco (segunda modernidade ou modernidade reflexiva).

BECK fundamenta a teoria da modernidade reflexiva sob o pálio de que se trata de um dado estrutural componente da sociedade, onde o processo de modernização é reflexivo ao passo que se executa, se efetiva e se espelha sobre si mesmo, trazendo de volta as consequências da degradação ambiental. Este fenômeno é denominado por BECK como efeito bumerangue: "contido na globalização, e sem embargo, claramente diferente dela, constituindo-se em um modelo de repartição dos riscos que afetam mais cedo ou mais tarde aqueles que os produziram ou se beneficiaram deles"3

É justamente o efeito bumerangue o fator de comprometimento do meiolambiente e da sustentabilidade agrícola, responsável pela alimentação da população mundial, instaurando situações de perigo social que afetam as diversas camadas da coletividade.

Paralelamente à teoria de Beck, GIDDENS justifica a crise ambiental advinda da modernidade reflexiva a uma alteração de valores e a uma crise das tradições, denominada pelo autor como ordem pós social-tradicional num contexto de sociedade culturalmente cosmopolita, que remete ao processo de globalização que não se apresenta como puramente econômico, mas como "uma mistura complexa de processos que frequentemente atuam de forma contraditória, produzindo conflitos, desarticulações e novas formas de estratificação"

Isto é, a globalização se relaciona diretamente com a rápida transformação do tempo e do espaço, promovendo a rápida comunicação e transporte de pessoas, de maneira que as atividades locais referentes à vida cotidiana dos sujeitos acabam por serem influenciadas e até mesmo determinadas por fatos ou instituições distantes, constituindo uma dinâmica de interdependência global ${ }^{5}$.

A informatização tem papel fundamental no processo de globalização, vez que desempenha relevante função na propagação de idéias e valores nos níveis regional,

\footnotetext{
${ }^{3}$ BECK. Sociedade de Risco... cit.

${ }^{4}$ VIOLA, E., LEIS, R., "Governabilidade e mudança climática: desafios e impasses globais e brasileiros", Ideias, UNICAMP/IFCH ,Campinas, v. 8, n. 2, p. 71-144, 2001.

${ }^{5}$ GIDDENS, A., "Admirável Mundo Novo: o novo contexto da política". Caderno CRH, Salvador, UFB/CRH, n. 21, p. 9-28, jul./dez. 1994.
} 
nacional e internacional, possibilitando acesso a dados e informações em tempo real, o que reforça ao coletivo humano um mundo de incertezas e de riscos produzidos. Este fator não significa a inexistência de riscos anteriormente, mas que a modernidade acrescenta a estes um componente de imprevisibilidade ao conhecimento e à intervenção humana sobre o meio ambiente.

A modernidade trouxe o equívoco pensamento de que quanto mais a humanidade se apropriasse da realidade social e física, mais apta estaria a controlá-la e utilizá-la em seu próprio interesse, o que é confrontado com a realidade de graves acidentes e catástrofes ambientais em proporções não experimentadas anteriormente ${ }^{6}$.

Para tanto é necessária a criação de políticas a serem formuladas por instituições públicas e privadas transnacionais, o que implica na multiplicação de práticas sociais embasadas na ampliação do direito à informação e da educação ambiental numa perspectiva integradora, oportunizando a participação da coletividade, agindo de forma democrática visando a emancipação social.

Trata-se de potencializar iniciativas por intermédio do acesso à informação e transparência na gestão dos problemas ambientais urbanos visando o desenvolvimento sustentável, analisando não apenas a capacidade de suporte do planeta, mas também os limites das ações voltadas à atenuação dos impactos neste cotidiano urbano.

O Estado tem o dever de se organizar de maneira a facilitar o acesso aos canais de participação, gestão e decisão dos problemas pela sociedade local e mundial, de forma a proporcionar a apreciação e real compreensão dos impactos desencadeados pela irresponsabilidade política no comando de processos econômicos de exploração dos recursos naturais em escala mundial.

Materializar o desenvolvimento sustentável é o grande desafio da sociedade contemporânea (a sociedade de risco), sendo indispensável a conexão entre políticas públicas ambientais e econômicas em todas as esferas de governo, nacional e internacionalmente. Ademais, o desenvolvimento social está enraizado na ideia de desenvolvimento sustentável, pois como já observava Henry David Thoreau ${ }^{7}$, contrapondo-se a Rousseau, não seria a harmonia existente na natureza que deveria ser

\footnotetext{
${ }^{6}$ GIDDENS, A., "A vida em uma sociedade pós-tradicional”, Beck, U. (dir), Modernização reflexiva: politica, tradição e estética na ordem social moderna, UNESP, São Paulo, 1997.

${ }^{7}$ ANTUNES, BESSA, P., Dano ambiental: uma abordagem conceitual, Lumen Juris, Rio de Janeiro, 2002, p. 41-52.
} 
buscada na sociedade por meio da vontade geral, o que levaria ao equilíbrio ambiental e consequentemente social, mas o respeito às minorias e à diferença. Um determinado ecossistema, para Thoreau, só se mantém em equilíbrio se houver a necessária atribuição de valor a todos os elementos que o compõe. Ao transportar este pensamento para a sociedade, o autor afirma que uma sociedade só será justa e equilibrada se respeitar a sua diversidade.

Por trás do necessário engajamento e participação social repousa a questão da cidadania e da democracia participativa de forma a exigir, tanto da sociedade quanto do Estado uma postura firme na proteção ambiental como fatores decisivos para impedir o retrocesso ecológico e o aumento dos riscos, alcançando-se a emancipação social.

Nesse sentido, a sociedade de risco procura repassar ao Estado o dever de proteção ao meio ambiente bem como a obrigação de adotá-la como critério e meta procedimental de suas decisões, o que não exime esta sociedade de sua parcela de responsabilidade.

Desta situação emergiu um novo Estado, o Estado Ambiental, que passou a reconhecer novos institutos e novas garantias, que convergem, necessariamente, para modificações profundas nas estruturas da sociedade organizada, de forma a direcionar e propiciar alternativas para a superação da atual crise ambiental, resguardando os valores que ainda existem e recuperando aqueles que deixaram de existir.

De acordo com José Joaquim Gomes CANOTILHO ${ }^{8}$, o Estado Ambiental é norteado pelos princípios ecológicos, se caracterizando pela participação política bifurcada entre Estado e comunidade, bem como pelo dever de promoção de políticas públicas econômicas, educativas e jurídicas embasadas nas exigências da sustentabilidade ecológica.

Assim, o Estado Ambiental funda a sua existência no interesse, tanto do Estado quanto da sociedade em tutelar efetivamente o meio ambiente, contendo as funções de promoção da qualidade de vida humana, a ética ambiental, a educação ambiental, a gestão participativa e a democracia ambiental.

Estas características do Estado Ambiental desencadearam o nominado "Estado ambiental cooperativo", que detém seu cerne na colaboração entre Estado e sociedade

\footnotetext{
${ }^{8}$ GOMES CANOTILHO, J. J., "Estado Constitucional Ecológico e Democracia Sustentada", CUNHA, S. S. da; GRAU, E. R., Estudos de Direito Constitucional em Homenagem a José Afonso da Silva, Malheros, São Paulo, 2003, p. 20.
} 
na proteção ambiental, principalmente na participação das forças sociais na formação da vontade político-ambiental e no processo decisório, reforçando o conteúdo democrático deste Estado.

Michael KLOEPFER ${ }^{9}$ afirma neste sentido:

A inclusão de particulares reforça, inicialmente, a consciência de responsabilidade das forças sociais pela proteção ao meio ambiente e se presta ademais à limitação do poder do Estado, o que diminui o risco de eliminação (parcial) das estruturas democráticas e dos direitos individuais à liberdade. Caso uma cooperação nos termos da delimitação acima descrita de tarefas estatais e sociais seja possível, ela, no entanto, cumpre o seu propósito essencialmente apenas quando os aportes da colaboração fundados no princípio da cooperação realmente repousarem na voluntariedade.

Dentro deste Estado Ambiental e cooperativista, o Direito Ambiental, por intermédio da efetivação de seus princípios e regras, assume essencial relevância na viabilização do bem estar da sociedade, exigindo alterações legislativas nas Constituições dos países que adotam este modelo.

Michael KLOEPFER ${ }^{10}$ ressalta que uma vez reconhecido o Estado Ambiental e estipulados novos princípios deve haver a compatibilidade da carta política aos modernos paradigmas jurídico-constitucionais que compõem a estrutura estatal.

A nova aparência que deve ser atribuída ao ordenamento jurídico se deve ao fato de que no Estado Ambiental e cooperativista o principal fundamento é o meio ambiente, ante o reconhecimento de que os recursos naturais vão além dos interesses econômicos, transformando a proteção ambiental em uma tarefa e um dever, tanto da coletividade quanto do Estado, funcionando como um mecanismo conjunto, visto que na medida em que a proteção social não se demonstra suficiente ao resguardo da natureza, deve o Estado intervir junto ao problema, impondo o interesse geral de tutela ambiental, haja vista que somente o ente estatal, em razão de seu monopólio de poder, dispõe de meios e poder para fazer cumprir o fundamento do Estado, que seria o equilíbrio do meio

\footnotetext{
${ }^{9}$ KLOEPFER, M., “A caminho do Estado Ambiental? A transformação do sistema político e econômico da República Federal da Alemanha através da proteção ambiental especialmente desde a perspectiva da ciência jurídica" (Tradução de Carlos Alberto Molinaro), em Ingo Sarlet, W., (Org.). Estado socioambiental e direitos fundamentais, Livraria do Advogado Editora, Porto Alegre, 2010, p. 69.

${ }^{10}$ KLOEPFER, “A caminho do Estado Ambiental? ... cit., p. 42.
} 
ambiente, conforme preconizado no artigo 225 da Constituição da República Federativa do Brasil.

No mundo capitalista, é notória a necessidade de imposição de regras que estabeleçam limites às atividades econômicas, orientando e influenciando o comportamento do mercado, restringindo e controlando suas ações referentes ao meio ambiente. Entretanto, se apresenta como inútil um direito que é ambiental, dentro de todo um sistema jurídico não ambiental, sendo esta a situação ambígua que tem vivido o microssistema jurídicoambiental brasileiro ${ }^{11}$.

Apresenta-se como indispensável uma inovação ao Direito Ambiental brasileiro, visando resguardar o direito fundamental ao meio ambiente sadio e equilibrado classificado como direito de terceira dimensão ${ }^{12}$ - devendo-se romper com os paradigmas tradicionais, exigindo uma renovação de conceitos e institutos jurídicos que se apresentem aptos à tutela desse novo direito da solidariedade e da cooperação.

Esta caminhada rumo ao Estado Ambiental provocada pelo agravamento da crise ecológica impõe que a sociedade inicie sua transformação, com a caracterização de uma nova forma de cidadania emergente, ato contínuo a um Estado com características inéditas em conjunto com um ordenamento jurídico ambiental apto a viabilizar e garantir a evolução da sociedade, através da busca da máxima efetividade de suas normas $^{13}$.

Note-se que a preocupação contemporânea da sociedade, e, por conseguinte, do Estado, reconhecendo a "existência tanto de uma dimensão social quanto de uma dimensão ecológica da dignidade (da pessoa) humana"14, estão refletidos na estrutura constitucional brasileira, condicionando a legitimidade das políticas públicas a serem

\footnotetext{
${ }^{11}$ PEREIRA DE SOUZA, P. R., “A Conflituosidade Ambiental do Desenvolvimento Econômico”, em Nasser Ferreira, J. S. A. B., Ribeiro, M. F., Direito Empresarial Contemporâneo, Arte \& Ciências, São Paulo, 2007. p. 269

12 Acerca dos direitos de terceira dimensão afirma Paulo Bonavides, que lhe atribui a nomenclatura de direitos de terceira geração: "um novo pólo jurídico de alforria do homem se acrescente historicamente aos da liberdade e da igualdade. BONAVIDES, P., Curso de Direito Constitucional, Malheiros, São Paulo, 1997. p. 523.

${ }^{13}$ BORGES CARDOSO BRASIEIRO, R., "Função ambiental do contrato: proposta de operacionalização de princípio civil para a proteção do meio ambiente", Revista de Direito Ambiental, Revista dos Tribunais, São Paulo, ano 13, n. 49, jan/mar, 2008. p. 11.

14 FENSTERSEIFER, T., SARLET INGO, W., "Estado socioambiental e mínimo existencial (ecológico?): algumas aproximações", em Sarlet Ingo, Estado socioambiental... cit., p. 16.
} 
adotadas, ao efetivo reconhecimento daquelas dimensões. Daí a preferência pelo termo "Estado Socioambiental".

Além do Direito, o Planejamento Urbano e o Urbanismo são peças fundamentais para a eficácia das intervenções sugeridas neste trabalho. O Urbanismo, com suas origens já na Grécia Antiga, quando no Século VI a. C. as cidades gregas já dispunham de critérios de ordenação da cidade, passa por um contínuo processo de mudança que será influenciado pelas conjunturas políticas e sociais de suas épocas, chegando aos Séculos XVII e XVIII sob forte influência francesa, que além de se preocupar com questões de estética, se volta às questões de saúde, circulação de ar, e ainda, procura aperfeiçoar a administração, daí se seguindo o fortalecimento da legislação, levando Harouel a afirmar que no final do século XVIII o direito do urbanismo já era um ramo do direito administrativo ${ }^{15}$.

A Revolução Industrial ocorrida entre os Séculos XVII e XIX leva uma nova realidade aos espaços urbanos, com o rápido crescimento de sua população e a consequente necessidade de atendimento das diversas demandas que se somavam às antigas. As respostas do urbanismo a essa realidade são variadas estão diretamente relacionadas com a atividade de planejamento urbano, também este com suas correntes - progressista, humanista e naturalista ${ }^{16}$. A atividade de planejamento urbano teve seu processo de evolução, e da mesma forma que o Direito e o Urbanismo, foi influenciada pelas conjunturas econômicas e políticas de cada época. Neste caminhar, havia a discussão se a teoria do planejamento deveria apenas analisar o planejamento em si ou se deveria ter uma posição normativa, prescritiva.

A ideia de planejamento hoje é de cunho constitucional, passando a ser um mecanismo jurídico na busca do atendimento das demandas sociais.

Para José Afonso da $\operatorname{SILVA}^{17}$ o planejamento (urbanístico) é um processo de elaboração de normas jurídicas, e não simplesmente um conceito técnico, cuja realização fica ao sabor do governante do momento.

No Brasil, diversos artigos na Constituição afirmam esta judicialização do planejamento, como é o caso do Orçamento, previsto nos artigos 165 e seguintes da

\footnotetext{
${ }^{15}$ HAROUEL, J.-L., História do urbanismo, (Trad. Ivone Salgado), Papirus, Campinas, 1990. p. 90.

${ }^{16}$ HALL, P., Cidades do amanhã, (Trad. Pérola de Carvalho), Perspectiva, São Paulo, 1995. p. 382-403.

${ }^{17}$ AFONSO DA SILVA, J., Direito urbanístico brasileiro, Malheiros, São Paulo, 2006. p. 94-96.
} 
Constituição Federal de 1988, o artigo 21, IX, que estabelece a competência da União para "elaborar e executar planos nacionais e regionais de ordenação do território e de desenvolvimento econômico e social", o artigo $174, \S 1^{\circ}$, que estabelece a lei como elemento definidor das diretrizes e bases do planejamento do desenvolvimento nacional equilibrado, no que toca à atividade estatal de atuação no domínio econômico, o artigo 30, VIII, que delega aos Municípios a competência para elaboração de um planejamento para promoção do adequado ordenamento territorial, isto é, do uso do solo.

Em relação à política urbana, a ideia de planejamento está inserida no caput do artigo 182 da Constituição da República que dispõe sobre a política de desenvolvimento urbano.

Art. 182. A política de desenvolvimento urbano, executada pelo Poder Público municipal, conforme diretrizes gerais fixadas em lei, tem por objetivo ordenar o pleno desenvolvimento das funções sociais da cidade e garantir o bem estar de seus habitantes.

$\S 1^{\circ} \mathrm{O}$ plano diretor, aprovado pela Câmara Municipal, obrigatório para cidades com mais de vinte mil habitantes, é o instrumento básico da política de desenvolvimento e de expansão urbana.

$\S 2^{\circ}$ A propriedade urbana cumpre sua função social quando atende às exigências fundamentais de ordenação da cidade expressas no plano diretor.

Deste modo, com a produção legislativa infraconstitucional que se seguiu após o ano de 1988 até a atualidade (2016), o sistema jurídico-urbanístico brasileiro encontra-se devidamente estruturado para permitir que a sociedade indique como deve ser o processo de ocupação do solo urbano.

Assim, as atividades a serem desenvolvidas devem estar de acordo com este sistema jurídico, permitindo um equilíbrio entre os diversos segmentos desta sociedade.

No capítulo seguinte pretende-se analisar uma destas atividades, que exerce grande influência no cotidiano de milhares de pessoas ao redor do mundo, apresentando detalhes da realidade contemporânea brasileira.

\section{RISCOS NA ATIVIDADE URBANA: A ATIVIDADE IMOBILIÁRIA}

Diante destas breves considerações acerca da sociedade de risco, do Estado Ambiental (ou Estado Socioambiental), e do planejamento urbano, sobre os quais têm se debruçado 
doutrina nacional e estrangeira, e diante das evidências sobre a necessidade da adoção de controles efetivos sobre a atividade econômica (citando como exemplos paradigmáticos a questão da logística reversa em relação aos resíduos sólidos, o acidente nuclear de Fukushima em 2011, e o deslizamento de terra em Shenzhen na China em 2015), é possível imaginar a continuidade de desastres ambientais ao longo dos anos. Não se trata de devaneios acadêmico-ecológicos. Por mais que se tente desqualificar o debate cujo assunto verse sobre a fragilidade do meio ambiente frente às possíveis novas conquistas tecnológicas em prol da sociedade, as recentes alterações climáticas ou a falta de peixes nas áreas afetadas por represas impõem a inclusão em pauta deste tema nas mais diversas esferas de discussão e deliberação, pública e privada. Como visto, os casos concretos variam do global ao local, e em todas estas frentes há a necessidade de uma atuação preventiva e reparadora voltada à busca de um equilíbrio ambiental, que por sua completude, abrange aspectos sociais, culturais, políticos, econômicos e jurídicos.

No esteio destas atuações, vale ressaltar os temas oficiais objeto de discussão na Conferência das Nações Unidas sobre Desenvolvimento Sustentável (Rio +20$)^{18}$, quando se pretendia rediscutir o tema ambiental, atualizar o debate em diversos temas e propor medidas concretas para o futuro.

Inobstante a alta relevância dos temas tratados nestes eventos, um tema parece ter sido sub-dimensionado nestes encontros. É a questão "urbana”.

Se por um lado é certo que eventos deste porte pretendam tratar de problemas globais, com a adoção de medidas de caráter transnacional, a questão urbana não deve tomar papel de menor destaque, na medida em que ela é causa e consequência desta sociedade de risco. Não que a população urbana, individualmente considerando seus componentes, seja responsável pelo risco criado, mas é que os destinatários dos produtos derivados das diversas atividades de risco estão geograficamente assentados nestes locais ${ }^{19}$, e o modelo de consumo e de atividades incentivado neste segmento populacional retroalimenta a produção de bens e serviços baseados em atividades de risco.

\footnotetext{
${ }^{18}$ A Rio + 20 realizou-se entre os dias 12 e 22 de Junho de 2012 no Rio de Janeiro, e teve como temas principais: (a) economia verde no contexto do desenvolvimento sustentável e a erradicação da pobreza, e (b) o quadro institucional para o desenvolvimento sustentável.

${ }^{19}$ Esta informação foi divulgada ao largo do ano de 2008. Já em 19/04/2007, a ONU, por meio da Rádio das Nações Unidas divulgava que a população mundial urbana havia superado os $50 \%$. Recuperado no dia 28 de maio de 2018 de, http://www.un.org/radio/por/story.asp?NewsID=2785.
} 
Tome-se como exemplo a atividade da construção civil no Brasil. Desde a crise financeira mundial de 2008/2009, as diversas instâncias de governo vêm procurando abrandar os efeitos desta crise adotando políticas possíveis dentro de suas respectivas esferas de competência.

No caso da instância federal de governo, dentre outras medidas, tem-se criado diversos mecanismos voltados a estimular a construção de moradias em todo o território nacional. Com efeito, o déficit habitacional tem se mostrado de grandes proporções e é dever constitucional de todos os entes federativos ${ }^{20}$ "promover programas de construção de moradias e a melhoria das condições habitacionais e de saneamento básico". Proporcionar mecanismos de desenvolvimento desta atividade tem grande relevância social, na medida em que viabilize moradias adequadas para a população que dela necessita de forma mais urgente ${ }^{21}$, e também promova o incremento da atividade da construção civil, que, sabidamente, gera benefícios econômicos diretos e indiretos no ambiental local dos Municípios.

Não se pretende neste trabalho analisar a efetividade dos programas em andamento, nem discutir o direito à moradia como direito humano fundamental ${ }^{22}$, mas enquadrar esta atividade como uma atividade que se desenvolve no ambiente local urbano, assim como tantas outras, permitindo demonstrar a tese de que a atividade de risco "mora ao lado”. Ela não está somente em Fukushima ou em Belo Monte ${ }^{23}$.

Seria então a atividade da construção civil uma atividade de risco?

Ora, partindo-se das premissas analisadas anteriormente neste trabalho, a sociedade de risco pressupõe a existência de diversas atividades com potencial de gerarem riscos à qualidade ambiental, social e econômica. Construir moradias e estabelecimentos comerciais em áreas urbanas é uma atividade legítima e importante no mundo contemporâneo, e que, se analisada individualmente, não ocasionaria maiores consequências negativas à sociedade. No entanto, a terra urbana hoje em dia encontra-se

\footnotetext{
${ }^{20}$ Constituição da República Federativa do Brasil, Art. 23, inciso IX.

${ }^{21}$ Esta afirmação tem conteúdo genérico e teórico. Tratar com a devida vênia a questão da moradia adequada pressupõe o reconhecimento do direito à cidade como gênesis do debate.

22 BEDESCHI, L., "O direito à moradia adequada em face de moradores de cortiço", Anais do VI Congresso Brasileiro de Direito Urbanístico. Brasília, 2010; ORG. NELSON SAULE JÚNIOR et al., Por um Direito Urbanístico sem fronteiras, Lex Magister, Porto Alegre:, 2010. p. 143.

23 Referência à polêmica construção da Usina Hidrelétrica de Belo Monte, no Rio Xingu, Região Amazônica do Brasil.
} 
bastante valorizada, na medida em que se mostrou ao capital como alternativa segura de investimento, fugindo dos cíclicos riscos financeiros globais. Esta perspectiva de aumento de capital se mostra mais atraente na proporção inversa de uma regulação adequada por parte do poder público na ocupação do solo urbano. Quanto maior liberdade para construir (gerando maior impacto ambiental negativo), maior a perspectiva de lucro.

\section{Martin SMOLKA ${ }^{24}$ explicita que}

[A] capacidade do capital incorporador atuar sobre a estruturação da cidade reflete uma subordinação do planejamento urbano aos imperativos da valorização capitalista; a força dessa atuação varia na razão inversa da existência de controle sobre o uso do solo e sobre as rendas fundiárias urbanas.

Esta atividade, que ao seguir os parcos e insuficientes instrumentos de regulação do solo geram o que se pode denominar de "destruição sistemática das cidades", pode ser considerada uma atividade de risco! Riscos visíveis e riscos invisíveis, pois uma ocupação desordenada do solo urbano pode gerar uma série de impactos negativos, como a falta de mobilidade, segregação socioespacial, falta de espaços com infraestrutura adequada para a construção de moradias populares, etc.

A qualidade de vida e a saúde da população urbana estão expostas a graves riscos em decorrência de uma problemática que interfere em seu próprio cotidiano, sobretudo nas grandes cidades sujeitas à urbanização de risco. Em todos os lugares há riscos, que se diferem apenas em espaço e em tempo, e que são distribuídos desigualmente entre os entes sociais, e onde a condição social de cada indivíduo o vincula a uma maior ou menor exposição aos riscos urbanos.

$\mathrm{Na}$ construção civil existem riscos identificáveis e riscos não identificáveis. Os riscos identificáveis são passíveis de controle e até mesmo de extirpação. Já no que tange aos riscos não identificáveis, estes devem ser definidos e caracterizados somente a partir de procedimentos técnicos, enfatizando a necessidade de sua comunicação ${ }^{25}$.

\footnotetext{
${ }^{24}$ SMOLKA, M., "O capital incorporador e seus movimentos de valorização". Cadernos IPPUR/UFRJ, jan-abril, n 1 ; PEREIRA, G. e SILVA, M. N. "Mercado imobiliário e estruturação do espaço na Região Metropolitana de Curitiba", Revista Metrópole n 18/2007.

${ }^{25}$ CASTELNOU NUNES, A., KANASHIRO, M., "Sociedade de risco, urbanização de risco e estatuto da cidade". Terra e cultura. Ano XX, $\mathrm{n}^{\mathrm{o}} 38$ 2010. Disponível em http://web.unifil.br/docs/revista_eletronica/terra_cultura/38/Terra\%20e\%20Cultura_38-12.pdf, p. 153.
} 
A construção de moradia na área urbana é uma espécie do gênero "utilização do solo urbano", dentro da qual tem se destacado a atividade de parcelamento do solo, que é o momento inicial para aquela atividade mencionada acima, de construção de moradias.

Esta atividade vem sendo regulada em nível nacional pela Lei n. 6.766/79, que dispõe sobre o parcelamento do solo urbano. Trata-se de norma editada pela União no exercício de sua competência constitucional para elaboração de normas gerais em matéria de competência urbanística (art. 24, I, § $1^{\circ}$ ).

Em consonância com estas normas gerais, Estados e Municípios vêm densificando as diretrizes legais e infralegais no sentido de compatibilizar o direito ao exercício de atividade econômica (incorporadoras e construtoras imobiliárias) com o direito ao meio ambiente ecologicamente equilibrado (coletividade).

Será o interesse a ser tutelado, portanto, que irá delimitar o âmbito de atuação legítima de cada ente federativo.

A importância da caracterização dos chamados interesses comuns (regionais) e interesses locais é ressaltada por Alaôr Caffé $\mathrm{ALVES}^{26}$, alertando ab initio que os interesses comuns não são o mero somatório dos interesses municipais adjacentes.

Os interesses locais ou peculiares, segundo entendimento da doutrina, observado por Sérgio FERRAZ ${ }^{27}$ já em 1976, não são aqueles de interesse exclusivo de um Município. Equivalem a interesse preponderantemente municipal. Em épocas atuais, quando se comenta a respeito da globalização ou mundialização dos interesses, fica mais claro observar que toda e qualquer atividade realizada em alguma parte do mundo vai ter menor ou maior consequência em outros locais.

Quando estes interesses não são preponderantemente municipais, verifica-se que a execução de determinados serviços ou funções devem ser executados regionalmente, pois, se deixados à iniciativa de cada Município, não terão tratamento globalmente satisfatório $^{28}$. Um exemplo desta situação diz respeito à coleta e tratamento do lixo.

\footnotetext{
${ }^{26}$ ALVES, A., "Regiões metropolitanas, aglomerações urbanas e microrregiões", Revista de Direito Ambiental n. 21, jan-mar/2001. p. 74.

${ }^{27}$ FERRAZ, S., “As regiões metropolitanas no direito brasileiro”, Revista de Direito Público, jan/jun, 1976. p. 21.

${ }^{28}$ FERRAZ, “As regiões metropolitanas...” cit. pp. 21-22.
} 
Volta-se aqui, portanto, à afirmação feita anteriormente neste trabalho, de que "os casos concretos variam do global ao local, e em todas estas frentes há a necessidade de uma atuação preventiva e reparadora voltada à busca de um equilíbrio ambiental, que por sua completude, abrange aspectos sociais, culturais, políticos, econômicos e jurídicos" (supra).

Em relação às medidas preventivas, quais são ou poderiam ser, efetivamente, estas medidas na atividade de parcelamento do solo urbano para fins comerciais?

Compensações para a aprovação do projeto? Esta opção vem sendo largamente utilizada pelos Municípios quando do exercício de suas competências constitucionais ao "promover, no que couber, adequado ordenamento territorial, mediante planejamento e controle do uso, do parcelamento e da ocupação do solo urbano", nos termos da Constituição da República Federativa do Brasil, art. 30, inciso VIII. Em atendimento ao interesse da coletividade, o impacto destes empreendimentos deve ser analisado, e em alguma medida deve ser compensado ou reduzido. Atualmente, um projeto de loteamento urbano é aprovado se o empreendedor construir uma creche, ou asfaltar uma rua, por exemplo.

Em geral, as compensações vêm sendo traduzidas em obras ou serviços voltados para a própria área urbana do Município (na maioria das vezes, perto dos empreendimentos), o que, se por um lado, permite a melhora do ambiente urbano, por outro, torna-se um fator de manutenção ou atração da população para estes locais em cujos espaços se deram as benfeitorias.

Este procedimento, se bem realizado, e baseado em estudos técnicos e com ampla participação popular, tem, efetivamente, o potencial de permitir uma melhoria da população urbana. Se não para toda ela, ao menos em parte do território.

Ocorre que, em algumas localidades, as medidas compensatórias adotadas em face de algum projeto e execução de parcelamento do solo urbano não conseguem alcançar seus resultados esperados, de melhoria do ambiente urbano, em face da constante atração de novos moradores para estes locais.

Somados a outros fatores, como congestionamentos, poluição e falta de planejamento urbano, o crescente aumento populacional pode prejudicar o crescimento econômico 
dos grandes centros urbanos na América Latina, conforme relatado em matéria veiculada na revista The Economist sobre os riscos das megacidades ${ }^{29}$.

E o Estado passa a ter maiores responsabilidades, uma vez que esta tendência de aumento populacional nas áreas urbanas vem se mantendo.

A concentração populacional é tão grande em determinados centros urbanos, que é possível indicar a estagnação ou a diminuição da população urbana como a melhor opção para a melhoria da qualidade de vida nestes locais.

Esta afirmação deve ser feita com cautela, sobretudo em época de gentrificação (ou elitização) promovida pelas diversas esferas de Poder, que, sob a rubrica de melhoria dos espaços urbanos, melhor circulação viária, em função dos mega eventos (Copa do Mundo em 2014, Olimpíadas em 2016), promovem verdadeiras limpezas étnicas nas áreas de maior valorização imobiliária ${ }^{30}$.

Propor o congelamento ou redução da densidade populacional de alguma área não pode ser entendido como disfarce para a reserva de espaços urbanos adequados destinados às parcelas da população que podem pagar o preço da terra urbana, cada dia mais caro ${ }^{31}$. $^{32}$

Esta constante atração para o espaço urbano é uma atividade de risco, na medida em que as consequências deste incremento populacional podem levar a uma série de consequências negativas, como: aumento do fluxo de trânsito, maior consumo energético, maior poluição atmosférica, dentre outras.

Partindo-se, portanto, de que a adoção de mecanismos de controle do incremento populacional é uma premissa correta, deve-se pensar quais medidas poderiam ser tomadas com o escopo de se impedir ou minimizar os riscos destas atividades.

\footnotetext{
29 MCKINSEY GLOBAL INSTITUTE. "Building globally competitive cities: The Key to Latin American Growth", The Economist. Disponível em: http://www.economist.com/node/21525915.

${ }^{30}$ Sobre o tema das remoções: http://www.viomundo.com.br/entrevistas/raquel-rolnik-removidos-pelosmegaeventos-sao-os-ultimos-a-saber.html.

${ }^{31}$ A empresa Global Property Guide, que orienta investidores em imóveis pelo mundo, indica que houve forte valorização dos imóveis em São Paulo. Recuperado no dia 02 de setembro de 2011 de, http://www.globalpropertyguide.com/investment-analysis/Global-housing-markets-under-pressure-saysGlobal-Property-Guide.

${ }^{32}$ Em janeiro de 2014, foi veiculado estudo sobre a valorização dos imóveis no Brasil, sendo a maior do mundo nos últimos 5 anos. Recuperado no dia 24 de janeiro de 2014 de, http://economia.estadao.com.br/noticias/economia-geral,valorizacao-de-imovel-no-brasil-foi-a-maior-domundo-nos-ultimos-5-anos, 175663,0.htm.
} 


\section{O URBANO INTERAGINDO COM O RURAL}

Por uma questão lógica, é sabido que os custos do empreendedor para a compensação em função do parcelamento do solo urbano não devem inviabilizar o próprio empreendimento imobiliário. No entanto, a gestão social da valorização da terra (ou a recuperação de mais valias urbanas) indica que parte dos lucros provenientes de empreendimentos imobiliários urbanos deve ser repartido com a sociedade ${ }^{33}$.

Neste sentido, tanto a autorização do Município para o parcelamento do solo urbano, quanto o aumento do perímetro urbano deste Município, gerando um aumento do valor da terra, têm como consequência o dever deste incremento financeiro experimentado pelo particular ser repartido com a coletividade, que não deverá suportar sozinha os riscos das atividades imobiliárias urbanas.

É sabido que a transformação de uma área rural para uma área urbana resulta, em regra, no aumento real do preço da terra. E esta alteração, na maioria das vezes se dá com a simples aprovação pela Câmara de Vereadores, de um projeto de lei para aumento do perímetro urbano.

Levando-se em consideração que as medidas compensatórias tradicionalmente adotadas pelos Municípios podem não trazer os resultados esperados, outras medidas deverão ser pensadas e executadas na busca deste objetivo da coletividade. $\mathrm{O}$ aumento de uma área urbana ou um parcelamento do solo poderá, portanto, ser compensado com o incentivo e desenvolvimento de uma área rural produtiva nas proximidades de onde se promoveu este aumento, de forma a garantir a sustentabilidade local ou regional, dependendo do caso. A oferta de moradia no ambiente urbano deve ser compensada com a possibilidade de permanência ou retorno da população às atividades do campo, evitando-se assim uma concentração excessiva da população na área urbana.

Esta contrapartida por parte do interessado no parcelamento do solo urbano poderia se dar de diversas maneiras, a depender da realidade de cada caso em concreto.

\footnotetext{
${ }^{33}$ Em geral, existem três medidas que podem ser tomadas pelo poder público e que geram uma mais valia nos imóveis urbanos: i) transformação de solo rural em solo urbano; ii) modificação do zoneamento urbano permitindo usos mais rentáveis do solo; iii) autorização para um maior coeficiente de aproveitamento. Vid. LEGUIZAMÓN, A. S. et al., Movilización social de la valorización de la tierra: casos latinoamericanos, Lincoln Institute of Land Policy. Cambridge, Massachussets, 2007. CD Rom; y ALTERMAN, R., "Can the "unearned increment" in land values be harnessed to supply affordable housing?”, 2009. Disponível em: http://alterman.technion.ac.il.
} 
Sistema semelhante já vem sendo utilizado quando da aplicação da outorga onerosa do direito de construir, previsto no artigo 28 e seguintes do Estatuo da Cidade, Lei federal $\mathrm{n}^{\mathrm{o}} 10.257 / 2001$. No Município de Curitiba/PR esta contrapartida pode se dar por meio de transferência de uma propriedade urbana $^{34}$ para o Município, com a finalidade de promover habitação de interesse social ${ }^{35}$.

Assim, concomitantemente com a autorização do parcelamento do solo urbano e construção de moradias e estabelecimentos comerciais que geram o afluxo permanente e temporário de pessoas, outra parte do Município terá este afluxo limitado, ao se destinar o uso do solo para atividades de baixa densidade demográfica, com um mínimo de alteração do meio ambiente. Ademais, estando estes espaços localizados nas franjas urbanas, é possível evitar a transformação de área rural para urbana, se houver áreas vazias no perímetro urbano, dotadas de infraestrutura, e que não demandam maiores investimentos por parte do poder público.

Pensar alternativas para modelos postos pode ser um caminho para a melhoria da qualidade de vida urbana e rural, desde que fundamentada em bases concretas e factíveis.

Ao contrário da agricultura chamada de "patronal", voltada para a expansão da produção e aumento da produtividade com emprego de tecnologia avançada, a agricultura familiar pode ser conceituada como aquela que enfatiza aspectos sociais e ambientais em sua atividade, coadunando-se, assim, com a ideia de desenvolvimento sustentável que vem sendo construído ao longo dos últimos 40 anos, ou seja, o desenvolvimento que busca equilibrar os aspectos econômicos, sociais e ambientais de qualquer atividade.

Destaque-se ainda a multifuncionalidade da escolha da agricultura familiar que "além de produzir alimentos e matérias-primas, gera mais de $80 \%$ da ocupação no setor rural e favorece o emprego de práticas produtivas ecologicamente mais equilibradas, como a

\footnotetext{
${ }^{34}$ Lei municipal no 7.420/90. Art. $3^{\circ}$ - Para a obtenção do incentivo construtivo, o interessado transferirá à Companhia de Habitação Popular de Curitiba-COHAB-CT, à conta do Fundo Municipal de HabitaçãoFMH, imóvel urbano destinado a programa habitacional de interesse social.

${ }^{35}$ Lei municipal no 11.266/2004- Plano Diretor de Curitiba. Art. 60, I.
} 
diversificação de cultivos, o menor uso de insumos industriais e a preservação do patrimônio genético"36.

Não se desconhece o fato de que o fomento às práticas agrícolas insere-se no âmbito da competência legislativa da União $^{37}$, no entanto, esta mesma Constituição atribui também aos Municípios a competência executiva para "fomentar a produção agropecuária e organizar o abastecimento alimentar", nos termos do art. 23, VIII, bem como definiu como ser de sua competência "legislar sobre assuntos de interesse local" e "promover, no que couber, adequado ordenamento territorial, mediante planejamento e controle do uso, do parcelamento e da ocupação do solo urbano" (artigo 30, I e VIII). A integração destas competências pode levar a um cenário adequado.

Ao se investigar os aspectos da agricultura familiar no Brasil e suas relações com o desenvolvimento urbano, não se pode esquecer duas grandes problemáticas: 1) êxodo rural; e 2) os impactos do "agrobusiness". Tais discussões não são as temáticas do presente artigo, todavia uma breve incursão nos mesmos poderá ajudar a contextualizar a importância desta política no campo para o desenvolvimento horizontal das cidades.

Segundo Ricardo ABRAMOVAY ${ }^{38}$ (2012), a partir dos anos 90, percebe-se uma forte alteração nas características do êxodo rural no Brasil. Houve uma diminuição da faixa etária dos migrantes, que de 40-50 anos, caiu para 15-19 anos. Além disso, a população que sai do campo em busca de oportunidades é em sua maioria do sexo feminino e tem em média apenas 4 (quatro) anos de escolarização ${ }^{39}$.

Essa massa migratória não é mais absorvida pelas cidades, contribuindo para a geração de miséria, excesso de mão de obra, favelização, violência, entre outros problemas urbanos contemporâneos.

\footnotetext{
${ }^{36}$ OLALDE RUIZ, A., Agricultura familiar e desenvolvimento "sustentável". Recuperado no dia 25 de junho de 2012 de, http://http://www.ceplac.gov.br/radar/Artigos/artigo3.htm.

${ }^{37}$ Constituição da República Federativa do Brasil de 1988:

Art. 22. Compete privativamente à União legislar sobre:

I - direito civil, comercial, penal, processual, eleitoral, agrário, marítimo, aeronáutico, espacial e do trabalho.

38 ABRAMOVAY, R., Agricultura Familiar e Desenvolvimento Territorial. Recuperado no dia 24 de setembro de 2012 de, ftp://ftp.sp.gov.br/ftpinstitutodeterras/abramovay.doc.
}

${ }^{39}$ ABRAMOVAY, Agricultura Familiar... cit. 
Com relação aos impactos do "agrobusiness", há ainda que se falar das contaminações por agrotóxicos e a dependência de multinacionais, principalmente a partir do uso das sementes transgênicas e todo o pacote de insumos necessários para o seu cultivo.

Entre os benefícios da agricultura familiar, verifica-se uma forte experiência de construção de capital social. Um exemplo disso é parceria realizada entre o Governo do Estado de Pernambuco e uma agência alemã de cooperação junto a 30 comunidades do interior desse Estado. O trabalho assalariado do "agrobusiness" foi substituído pelo empoderamento dos pequenos produtores, que com baixa quantidade de capital, conseguiram adquirir terra e insumos. Os indicativos demonstram um incremento na economia local, com a redução de custos de transação nos negócios, organização da comunidade, geração de renda (os agricultores deixaram de ser assalariados e passaram a ter renda superior a anterior, com melhores condições de trabalho) ${ }^{40}$.

Quando se fala em agricultura familiar no Brasil trata-se de atividades que vão desde a produção de alimentos orgânicos, industrializados - como queijos e vinhos -, artesanato, hortaliças, frutas, merenda escolar, turismo, e uma diversidade de produtos, já que a dimensão continental brasileira proporciona uma variedade de qualidades e produtos sequer imagináveis em outros países.

Aí entra a capacidade de construção de novos territórios, a capacidade dos atores econômicos locais valorizarem os ativos específicos das regiões que habitam ${ }^{41}$.

Em 25 de novembro de 1999 foi criado o Ministério do Desenvolvimento Agrário. Em sua estrutura administrativa, encontra-se a Secretaria de Agricultura Familiar, responsável pelo fomento desta atividade. Dentre os programas existentes, elencam-se aqueles que mais interessam para os objetivos deste trabalho ${ }^{42}$.

O Programa Nacional de Alimentação Escolar ${ }^{43}$ traz incentivos para que as Secretarias de Educação (municipais e estaduais) comprem produtos direto dos produtores agrícolas locais. Em um primeiro momento, a Secretaria de Educação deverá mapear os produtos, as quantidades e época de produção dos mesmos. Após esse levantamento, uma

\footnotetext{
${ }^{40}$ ABRAMOVAY, Agricultura Familiar... cit.

${ }^{41}$ ABRAMOVAY, Agricultura Familiar... cit.

42 BRASIL. Ministério do Desenvolvimento Agrário. Secretaria de Agricultura Familiar. Recuperado no dia 24 de setembro de 2012 de, http://www.mda.gov.br/portal/saf/.
}

43 BRASIL. Programa Nacional de Alimentação Escolar. Disponível em: http://www.fnde.gov.br/programas/alimentacao-escolar/alimentacao-escolar-apresentacao. 
nutricionista elaborará um cardápio, respeitando os hábitos alimentares locais e as necessidades nutricionais, a partir dos alimentos localmente produzidos.

Segundo dados da Confederação Nacional de Municípios, mais de 60\% dos municípios brasileiros compram alimentos da agricultura familiar para a merenda escolar. Assevere-se que, conforme a Lei 11.947/2009, 30\% dos recursos do Programa Nacional de Alimentação Escolar - PNAE devem ser gastos com esses produtos. (Municípios, 2012)

Já o Programa Agroindústrias visa à inclusão dos agricultores familiares no processo de agroindustrialização e comercialização de sua produção. Podem participar agricultores familiares e, no mínimo $70 \%$ da matéria prima deve ser própria.

Dentre os projetos da Secretaria, o que mais possui recursos financeiros é o PRONAF Programa Nacional de Fortalecimento da Agricultura Familiar. O mesmo é voltado à disponibilização de crédito, o qual pode ser pago em até dez anos, com três anos de carência e juros de $2 \%$ ao ano. Para projetos de até $\mathrm{R} \$ 10.000,00$ (dez mil reais) os juros são de $1 \%$ ao ano.

Importante asseverar que todas essas medidas não trazem benefícios apenas para os moradores do campo, já que com o desenvolvimento da agricultura familiar e a formação de capital social, as cidades da região produtora também passam a colher os frutos dessa forma horizontalizada de organização humanitária. As relações tornam-se mais fortes, baseadas em autoestima, valorização do conhecimento e culturas próprias, identificação de vocações regionais, redes de relacionamento, extinção da figura do atravessador, diminuição do êxodo rural, entre outros benefícios. E todos esses elementos contribuem para que os bens produzidos entrem com valor agregado do local de produção e alcancem a distribuição no mercado globalizado.

Em relação à proposta do presente trabalho, de fomento à agricultura familiar em áreas urbanas ou periurbanas, deve-se ressaltar a importância da convivência entre grupos sociais diferentes em um mesmo espaço territorial, como elemento reconhecedor da diversidade e fundamento de uma sociedade justa. Admitir que a cidade é para todos vem sendo o discurso adotado por sociedades democráticas e progressistas.

Ademais, na atualidade, é profícua a produção doutrinária e legislativa quanto ao que se convencionou chamar "habitação de interesse social", com suas Zonas Especiais de Interesse Social - ZEIS e Planos Locais de Habitação de Interesse Social - PLHIS, cuja 
essência passa também pelo reconhecimento da cidade para todos e a diversidade de usos e grupos sociais como elemento de coesão da sociedade.

Harold CARTER ${ }^{44}$, ainda em 1981, analisou o fenômeno de utilização mista das áreas onde ocorreu a expansão urbana, discorrendo que estas áreas apresentam-se como portadoras de características distintas, uma vez que somente parte do seu espaço foi assimilada pelo crescimento urbano, sendo que o restante continua sendo espaço caracterizado pelo mundo rural.

Nesta seara, se estabeleceu uma nova realidade caracterizada pela enorme diferenciação social, que se traduz na coexistência, nestas franjas, de mutações socioculturais permanentes e de transições "rural-urbano" constantes. Ressalta o autor: "Os "novos" residentes tendo vindo de um meio essencialmente urbano difundem valores e atitudes citadinas, enquanto os que viveram sempre em meio essencialmente rural assimilam, em maior ou menor grau, o modus vivendi dos "urbanos" recém-chegados"45.

E complementa ${ }^{46}$ :

Este é o processo que gerou o uso do solo que caracteriza a franja, o qual não está somente associado ao tipo de crescimento metropolitano; é caracterizado por uma grande heterogeneidade de usos do solo, que vão desde as antigas e intocadas vilas rurais às urbanizações modernas. (Carter, 1981, p. 68).

Com base em Michael CONZEN ${ }^{47}$, uma conceituação de "franjas urbanas" é apresentada por Karin MENEGUETTI e Renato REGO ${ }^{48}$ :

Ainda que descontínuos e soltos, os urban fringe belts (franjas urbanas) continuam representando espacialmente os ciclos do crescimento urbano em sua ação centrífuga. Via de regra, esses ciclos mostram a alternância entre anéis residenciais extensivos e de expansão veloz, durante períodos de boom econômico com abundante investimento de capital privado, e acréscimos de uso misto do solo urbano, mais lentamente materializados, quando o investimento privado se retrai ou

\footnotetext{
${ }^{44}$ CARTER, H., The rural urban fringe. The study of urban geography, Edward Arnold, London, 1981.

${ }^{45}$ CARTER, The rural urban ... cit. p. 67.

${ }^{46}$ CARTER, The rural urban ... cit. p. 68.

${ }^{47}$ CONZEN, M., How growing cities internalize their old urban fringes: a cross-cultural comparison, INTERNATIONAL SEMINAR ON URBAN FORM, 2008, Artimino. Proceedings... Artimino: ISUF, 2008. (Meio digital).

${ }^{48}$ MENEGUETTI SCHWABE, K., REGO, LEÃO R., "A respeito de morfologia urbana. Tópicos básicos para estudos da forma da cidade", Acta Scientiarum. Technology. Maringá: v. 33 n. 2, p. 123-127, 2011, p. 3.
} 
busca terras mais baratas, mas o investimento público ainda se mantém e favorece ou responde pelo aparecimento de melhorias de infraestrutura e de equipamento institucional, como escolas, hospitais, áreas esportivas, edifícios religiosos, cemitérios etc. Enquanto expansões residenciais têm caráter 'planejado', as franjas urbanas, que elas acabam por criar, têm natureza, no geral, 'espontânea'. E essas franjas, ao invés de se fundirem à massa urbana quando elas deixam de ocupar a periferia da cidade, retêm e até aumentam o seu caráter distintivo dentro da área edificada.

Ora, neste sentido, o estímulo à agricultura familiar nestas áreas denominadas "franjas urbanas" também se apresenta como viável. Vale ressaltar que esta ocupação territorial não traz benefícios apenas para os moradores do campo, uma vez que, com o desenvolvimento da agricultura familiar e a formação de capital social, as cidades da região produtora também passam a colher os frutos desta forma "horizontalizada" de organização.

Outros espaços de produção nos moldes da agricultura familiar que poderiam se enquadrar nesta hipótese são aqueles localizados no interior do perímetro urbano, e que são destinados ao cultivo de alimentos. Tal experiência vem sendo feita em diversos países, inclusive no Brasil. Benefícios e dificuldades foram apresentados em recente estudo $^{49}$, permitindo-se verificar a compatibilidade com o modelo ora exposto. Com efeito, alguns desafios se apresentam em relação aos casos estudados nos Estados Unidos quanto aos chamados Community Land Ttrust (CLT), ou "fideicomisso de solo comunitário", onde a população local utiliza espaços nas áreas urbanas para cultivarem hortas comunitárias.

Neste particular exemplo, o principal desafio apontado por $99 \%$ dos entrevistados em pesquisa realizada em $1988^{50}$, diz respeito à propriedade ou posse da terra. Se não houver segurança da posse ou propriedade, as leis de mercado fazem pressão para que haja um aproveitamento econômico ótimo para o terreno, não levando em consideração ganhos secundários como "saúde pública e bem estar da comunidade" ${ }^{51}$.

\footnotetext{
${ }^{49}$ YUEN, J. "Granjas urbanas en los fideicomisos de suelo comunitarios (CLT)", Land Lines, Lincoln Institute of Land Policy, 2014. Recuperado no dia 25 de setembro de 2014 de, https://www.lincolninst.edu/pubs/d1/2385_1726_Granjas_urbanas_0414LLSP.pdf.

${ }^{50}$ YUEN, “Granjas urbanas en los fideicomiso..." cit, p. 2.

${ }^{51}$ YUEN, “Granjas urbanas en los fideicomiso..." cit, p. 2.
} 


\section{CONCLUSÕES ARTICULADAS}

A Natureza, com sua diversidade de ecossistemas, é sábia ao demonstrar que não há interferência inócua no meio ambiente. As diversas e constantes alterações ambientais vêm demonstrando a necessidade de se adotar práticas que levem em consideração a capacidade de suporte destes ecossistemas, mantendo-se e melhorando a qualidade do ambiente em que vivem as populações.

O modo de produção da sociedade contemporânea encontra-se em um estágio diferenciado ao da sociedade pré-industrial do Século XIX, quando se tinha maior conhecimento dos impactos ambientais causados pelas atividades de então.

Atualmente tem-se uma grande variedade destas atividades, bem como o potencial de lesividade tem aumentado exponencialmente. Acrescente-se a este cenário os riscos que podem permanecer invisíveis, imperceptíveis, surgindo o que se convencionou chamar de sociedade de risco. Apresenta-se uma fase no desenvolvimento contemporâneo onde os riscos sociais, políticos, econômicos e individuais caminham para a possibilidade de perda de controle.

É neste cenário que se constrói a ideia de sustentabilidade ou de desenvolvimento sustentável, que, se não são expressões com o mesmo significado, indicam a necessidade de se adequar as múltiplas atividades efetuadas ao redor do mundo aos diversos interesses existentes nas sociedades contemporâneas, Um modo de vida não se sustenta tanto temporalmente, quanto qualitativamente, se promover o desequilíbrio em outro modo de vida. É um jogo de "soma zero", onde para uma parte de desenvolver, outra deve retroceder.

Em função desta situação, a sociedade vem desenvolvendo alguns mecanismos voltados e enfrentar tais questões, destacando-se neste trabalho as ciências do Direito e do Planejamento Urbano. Ao atuarem de forma conjunta, com base em premissas que valorizam a preservação ambiental, a diversidade cultural e reconhecem a necessidade de proteção frente às fragilidades de determinados segmentos sociais, estes ramos do conhecimento tem o potencial de induzir o processo de desenvolvimento urbano de forma equilibrada, conformando as diversas variáveis existentes nestes espaços: econômica, social e ambiental.

O Planejamento Urbano visa, portanto, analisar os aspectos positivos e negativos dos empreendimentos a serem executados na área urbana, objeto de análise deste trabalho, 
direcionando as atividades privadas e públicas, na busca da satisfação dos interesses individuais e coletivos. O Direito, capturando os anseios dos segmentos da sociedade, apresenta a tábua axiológica para determinado tempo e espaço, dando legitimidade às diversas atividades a serem desenvolvidas.

Uma das possibilidades de atuação do Planejamento Urbano e do Direito é a imposição de condicionantes de legalidade para as atividades imobiliárias urbanas que possam se constituir um risco para o equilíbrio socioambiental das localidades onde se situam.

Se determinado empreendimento imobiliário pode gerar uma maior concentração demográfica naquela região, é possível que como medida compensatória outra região seja reservada para uma menor densidade demográfica.

Se este empreendimento pode gerar um risco de alteração do ecossistema daquela localidade, preserva-se outra localidade que possa compensar as funções daquele ecossistema alterado.

Assim os riscos de um crescimento demográfico insustentável e de uma alteração ambiental podem ser mitigados ou compensados com medidas de restrição deste aumento demográfico e de preservação ambiental.

Aqui se sugere o incentivo às atividades denominadas de agricultura familiar, que pelas características apontadas anteriormente, tem o potencial de promover a mitigação ou compensação sugerida acima, bem como trazer outros benefícios à população do Município como um todo.

Adicionalmente, o incentivo à agricultura familiar nas franjas urbanas, ou ainda nos centros urbanos, pode gerar outros benefícios à população, como a redução de preço dos alimentos produzidos nesta zona rural incentivada, face à proximidade do mercado consumidor, melhoria da qualidade do produto, com utilização de práticas menos poluentes, ou uma maior interação entre os diversos segmentos da sociedade.

Se o desenvolvimento sustentável pressupõe o equilíbrio, não só em seu aspecto econômico, mas também nos aspectos social e ambiental, toda e qualquer atividade, pública ou privada, deve se pautar na efetivação deste princípio.

\section{REFERÊNCIAS BIBLIOGRÁFICAS}


ABRAMOVAY, R.. Agricultura Familiar e Desenvolvimento Territorial. Recuperado no dia 24 de setembro de 2012 de, < $\mathrm{ftp}: / / \mathrm{ftp}$. sp.gov.br/ftpinstitutodeterras/abramovay.doc $>$

AGGA (American Community Gardering Association). 1988. National Community Gardering $\quad$ Survey: $1996 . \quad$ Disponível $<$ http://www.communitygarden.org/docs/learn/cgsurvey96part1.pdf\%20>

ALTERMAN, R. Can the "unearned increment" in land values be harnessed to supply affordable housing? Disponível em: <http://alterman.technion.ac.il >

ALVES, A., "Regiões metropolitanas, aglomerações urbanas e microrregiões", Revista de Direito Ambiental n. 21, jan-mar/2001.

ANTUNES. P. B. Dano ambiental: uma abordagem conceitual, Lumen Juris, Rio de Janeiro, 2002.

BECK, U.; POFERL, A.. Grobre armut, grober reichtum: zur transnationalisierung sozialer ungleichheit, Suhrkamp, Fankfurt/Main, 2010.

BECK, U. Sociedade de Risco: rumo a uma outra modernidade, (Tradução de Sebastião Nascimento), Ed. 34, São Paulo, 2010.

BEDESCHI, L., "O direito à moradia adequada em face de moradores de cortiço", Anais do VI Congresso Brasileiro de Direito Urbanístico. Brasília 2010: por um Direito Urbanístico sem fronteiras. Org. Nelson Saule Júnior et al., Lex Magister, Porto Alegre, 2010 .

BONAVIDES, P., Curso de Direito Constitucional, Malheiros, São Paulo, 1997.

BORGES CARDOSO BRASIEIRO, R., "Função ambiental do contrato: proposta de operacionalização de princípio civil para a proteção do meio ambiente", Revista de Direito Ambiental, Revista dos Tribunais, São Paulo, ano 13, n. 49, jan/mar, 2008.

BRASIL. Ministério do Desenvolvimento Agrário. Secretaria de Agricultura Familiar. Recuperado no dia 24 de setembro de 2012 de, <http://www.mda.gov.br/portal/saf/>

- Programa Nacional de Alimentação Escolar. Disponível em: $<$ http://www.fnde.gov.br/programas/alimentacao-escolar/alimentacao-escolarapresentacao> 
CANOTILHO GOMES, J. J., "Estado Constitucional Ecológico e Democracia Sustentada", CUNHA, S. S. da; GRAU, E. R,. Estudos de Direito Constitucional em Homenagem a José Afonso da Silva, Malheiros, São Paulo, 2003.

CARTER, H. "The rural urban fringe", The study of urban geography, Edward Arnold, London, 1981.

CASTELNOU NUNES, A., KANASHIRO, M., "Sociedade de risco, urbanização de risco e estatuto da cidade". Terra e cultura. Ano XX, no 38 2010. Disponível em: < http://web.unifil.br/docs/revista_eletronica/terra_cultura/38/Terra\%20e\%20Cultura_3812.pdf $>$

CONZEN, M., "How growing cities internalize their old urban fringes: a cross-cultural comparison", INTERNATIONAL SEMINAR ON URBAN FORM, 2008, Artimino. Proceedings... Artimino: ISUF, 2008. (Meio digital).

FENSTERSEIFER, T., SARLET INGO, W., "Estado socioambiental e mínimo existencial (ecológico?): algumas aproximações", SARLET INGO, W., Estado socioambiental e direitos fundamentais, Livraria do Advogado Editora, Porto Alegre, 2010.

FERRAZ, S., “As regiões metropolitanas no direito brasileiro", Revista de Direito Público, JAN/JUN, 1976.

GIDDENS, A. "Admirável Mundo Novo: o novo contexto da política”, Caderno $C R H$, UFB/CRH, Salvador, n. 21, p. 9-28, jul./dez. 1994.

GIDDENS, A., “A vida em uma sociedade pós-tradicional” BECK, U.; GIDDENS, A.; LASH, S. Modernização reflexiva: política, tradição e estética na ordem social moderna, UNESP, São Paulo, 1997.

HALl, P., Cidades do amanhã, (Trad. Pérola de Carvalho), Perspectiva, São Paulo,1995.

HAROUEL, J-L., História do urbanismo, (Trad. Ivone Salgado), Papirus, Campinas, 1990.

LEAL, V. N., Coronelismo, enxada e voto, Alfa-Omega, São Paulo, 1975. 
LEGUIZAMÓN, A. S. et al, Movilización social de la valorización de la tierra: casos latino-americanos, Lincoln Institute of Land Policy, Cambridge/Massachussets, 2007. (CD Rom)

KLOEPFER, M., "A caminho do Estado Ambiental? A transformação do sistema político e econômico da República Federal da Alemanha através da proteção ambiental especialmente desde a perspectiva da ciência jurídica”, (Tradução de Carlos Alberto Molinaro), INGO SARLET, W., (Org.). Estado socioambiental e direitos fundamentais, Livraria do Advogado Editora, Porto Alegre, 2010.

MCKINSEY GLOBAL INSTITUTE. "Building globally competitive cities: The Key to Latin American Growth", The Economist. Disponível em: $<$ http://www.economist.com/node/21525915>

MENEGUETTI SCHWABE, K., REGO, LEÃO R., “A respeito de morfologia urbana. Tópicos básicos para estudos da forma da cidade", Acta Scientiarum. Technology. Maringá: v. 33 n. 2, p. 123-127, 2011.

MUNICÍPIOS compram da agricultura familiar e ajudam o desenvolvimento do setor. Portal da Confederação Nacional de Municípios. De 03 de abril de 2012. Recuperado no dia 23 de setembro de 2102 de, $<$ http://www.cnm.org.br/index.php?option=com_content\&view=article\&id=19747:mun icipios-compram-da-agricultura-familiar-e-ajudam-no-desenvolvimento-dosetor\&catid=70:destaques\&Itemid=118>

OLALDE RUIZ, A., "Agricultura familiar e desenvolvimento" sustentável”. Recuperado no dia 25 de junho de 2012 de, $<$ http://http://www.ceplac.gov.br/radar/Artigos/artigo3.htm>

SCHMELZKOPF, K., "Urban community gardens as contested space". Geographical Review 85(3), 1995, p. 364-381.

AFONSO DA SILVA, J., Direito urbanístico brasileiro, Malheiros, São Paulo, 2006.

PEREIRA DE SOUZA, P. R.,“A Conflituosidade Ambiental do Desenvolvimento Econômico", NASSER FERREIRA, J. S. A. B., RIBEIRO, M. F., Direito Empresarial Contemporâneo, Arte \& Ciências, São Paulo, 2007.

SMOLKA, M., "O capital incorporador e seus movimentos de valorização", Cadernos IPPUR/UFRJ, jan-abril, $\mathrm{n}^{\circ} 1$, PEREIRA, G., SILVA, M. N. "Mercado imobiliário e 
estruturação do espaço na Região Metropolitana de Curitiba", Revista Metrópole $\mathrm{n}^{\circ}$ $18 / 2007$.

VIOLA, E. LEIS, H., "Governabilidade e mudança climática: desafios e impasses globais e brasileiros", Ideias, UNICAMP/IFCH, Campinas, v. 8, n. 2, p. 71-144, 2001.

YUEN, J., "Granjas urbanas en los fideicomisos de suelo comunitarios (CLT)", Land Lines, Lincoln Institute of Land Policy, 2014. Recuperado no dia 25 de setembro de 2014 de, $<$ https://www.lincolninst.edu/pubs/d1/2385_1726_Granjas_urbanas_0414LLSP.pdf $>$ 